\title{
Potential Viroporin Candidates From Pathogenic Viruses Using Bacteria-Based Bioassays
}

\author{
Prabhat Pratap Singh Tomar ${ }^{+}{ }^{-}$, Rivka Oren ${ }^{\dagger}$, Miriam Krugliak and Isaiah T. Arkin *(D) \\ Department of Biological Chemistry, The Alexander Silberman Institute of Life Sciences, The Hebrew University \\ of Jerusalem, Edmond J. Safra Campus Givat-Ram, Jerusalem 91904, Israel \\ * Correspondence: arkin@huji.ac.il \\ † These authors contributed equally to this work.
}

Received: 30 April 2019; Accepted: 5 July 2019; Published: 9 July 2019

check for updates

\begin{abstract}
Viroporins are a family of small hydrophobic proteins found in many enveloped viruses that are capable of ion transport. Building upon the ability to inhibit influenza by blocking its archetypical M2 $\mathrm{H}^{+}$channel, as a family, viroporins may represent a viable target to curb viral infectivity. To this end, using three bacterial assays we analyzed six small hydrophobic proteins from biomedically important viruses as potential viroporin candidates. Our results indicate that Eastern equine encephalitis virus 6k, West Nile virus MgM, Dengue virus 2k, Dengue virus P1, Variola virus gp170, and Variola virus gp151 proteins all exhibit channel activity in the bacterial assays, and as such may be considered viroporin candidates. It is clear that more studies, such as patch clamping, will be needed to characterize the ionic conductivities of these proteins. However, our approach presents a rapid procedure to analyze open reading frames in other viruses, yielding new viroporin candidates for future detailed investigation. Finally, if conductivity is proven vital to their cognate viruses, the bio-assays presented herein afford a simple approach to screen for new channel blockers.
\end{abstract}

Keywords: viral channels; bacterial assays; channel blockers; anti-viral drugs

\section{Introduction}

Many important viruses have been shown to contain small hydrophobic proteins that are capable of ion channel activity. Members of this family have therefore been collectively termed viroporins [1-6]. The best-characterized member of the viroporin family is the influenza M2 channel $[7,8]$. The protein garnered significant interest when it was shown to be the target of the aminoadamantanes, anti-viral drugs [9]. The mode of action of amantadine and rimantadine was subsequently shown to be blockage of the $\mathrm{H}^{+}$channel activity of M2 [10].

Structurally, Influenza A M2 is a single-pass membrane protein that homo-tetramerizes to form the active protein complex [11]. X-ray crystallography, solution NMR, and solid-state NMR studies were able to derive structures of the transmembrane four-helix bundle [12-14]. Finally, since other viroporins are thought to possess a single transmembrane stretch, they may adopt a helical bundle structure, akin to the structure of M2.

Other than M2 from Influenza A, there are other examples of viroporins that have been characterized to a varying extent, amongst which one might mention: BM2 from Influenza B virus [15,16], CM2 from Influenza C [17,18], vpu from HIV-1 [19-21], p7 from Hepatitis C virus [22,23], Delta peptide from Ebola virus [24], NS2B from Japanese encephalitis virus [25] and from Dengue Virus [26], NS3 from bluetongue virus [27], and SH protein from human respiratory syncytial virus $[28,29]$. Finally, it is important to note that the importance of the channel activity of some of the aforementioned viroporins has been questioned in relation to the protein's role in viral infectivity [30]. 
Ion channels, in general, have long been used as excellent targets for pharmaceutical point intervention. Therefore, identification of ion channels in viruses led to the hope that channel blockers may prove beneficial as anti-viral agents, as is the case in Influenza's M2 channel [10]. Taken together, it is of no surprise that efforts are being spent to develop additional channel blockers against M2 and other viroporins [31-35].

The above examples have prompted us to search for additional viroporin candidates. As targets, we searched a select set of biomedically important viruses. These viruses we selected based on their pathogenicity, and paucity of channel characterization. In particular, we decided to focus on Eastern equine encephalitis (EEE) virus, West Nile virus, Dengue virus, and Variola virus. Scanning viral genomes and employing bacteria-based assays enabled us to identify six small proteins as potential viroporins.

EEE virus is a member of the Alphavirus genus, which is part of the Togaviridae, a family of positive-sense single-stranded RNA viruses. Other members of Togaviridae include Semliki Forest viruses, Ross River virus, Chikungunya virus, Sindbis virus, Rubella virus, and Barmah Forest virus. As a mosquito-transmitted disease, Eastern equine encephalitis impacts a large number of different hosts, and in humans causes encephalitis with a considerable mortality rate (33\%), and appreciable brain damage amongst the survivors [36].

The West Nile virus is the etiological agent of the mosquito-borne West Nile fever, which has been reported all over the world, and against which there is currently no vaccine or medication [37]. Mortality rates among infected individuals in which the nervous system has been impacted are around $10 \%$. In terms of taxonomy, the West Nile virus is a member of the Flavivirus genus within the Flaviviridae positive-sense single-stranded RNA viruses. The family contains other pathogens of biomedical importance, such as Dengue virus (see below), Yellow fever virus, and Zika virus.

The Dengue virus has represented an important health threat in recent times. It has been estimated that more than a third of the world population is located in regions in which Dengue fever is prevalent. The number of worldwide infections approaches 100 million annually, of which 500,000 results in dengue hemorrhagic fever and 22,000 in death [37].

Throughout the ages, smallpox has been one of the deadliest diseases known to man. In what has been heralded as a victory of modern medicine, it was completely eradicated in 1977, yet research continues since the virus remains a biological weapon threat. Variola virus, the etiological agent of smallpox, is a member of the Orthopoxvirus genus, which is part of the Poxviridae family of double-stranded DNA viruses [38].

\section{Materials and Methods}

\subsection{Protein Search}

Protein sequences from Eastern equine encephalitis virus, West Nile virus, Dengue virus, and Variola virus were extracted from the NCBI database. Subsequently, potential viroporins were identified using Phobius-a combined transmembrane topology and signal peptide predictor $[39,40]$. The method is based on a hidden Markov model that examines different regions within the signal peptide and the transmembrane segments. Transmembrane proteins shorter than one hundred amino acids were chosen for further analyses, as listed in Table 1. Additional transmembrane segment prediction algorithms were subsequently employed on the hits obtained from Phobius (TMpred [41] and MEMSAT [42]).

\subsection{Bacterial Strains}

Four strains of K12 Escherichia coli were used in the current study: DH10B, LB650, NT326, and LR1. DH10B cells were purchased from Invitrogen (Carlsbad, CA). LB650 bacteria ( $\Delta t r k G, \Delta t r k H$, and $\triangle k d p A B C 5$ system) contain deletions in genes connected to potassium uptake [43] and were a kind gift from Professor K. Jung (Ludwig-Maximilians Universität München) and Professor G.A. Berkowitz 
(University of Connecticut). NT326 bacteria ( $\triangle$ malE) lack an endogenous maltose binding protein (MBP) and were a kind gift from Professor D.M. Engelman (Yale University). LR1 bacteria contained a chromosomal copy of a $\mathrm{pH}$-sensitive green fluorescence protein (GFP) called pHluorin [44] and were a kind gift from Professor M. Willemoës and Professor K. Lindorff-Larsen (University of Copenhagen).

\subsection{Plasmids}

All proteins were expressed as fusion proteins to the maltose binding protein using the pMAL-p2X plasmid (New England Biolabs, Ipswich, MA). Genes for corresponding proteins have been added with a nucleotide sequence coding for linker of seven amino acids, six histidines, and a stop codon at the $3^{\prime}$ end. EcoRI and XbaI restriction sites were located at the $5^{\prime}$ and $3^{\prime}$ ends, respectively. The sequences were synthesized by GenScript (Piscataway, NJ). Protein expression was achieved by adding isopropyl $\beta$-D-1-thiogalactopyranoside (IPTG) to the growth media, as indicated.

\subsection{Chemicals}

IPTG was purchased from Biochemika-Fluka (Buchs, Switzerland). All other chemicals were purchased from Sigma-Aldrich laboratories (Rehovot, Israel).

\subsection{Growth Media}

Lysogeny Broth (LB) was used for all bacterial growth [45], unless noted otherwise. LBK was similar to $\mathrm{LB}$ expect that $\mathrm{KCl}$ replaces $\mathrm{NaCl}$ at $10 \mathrm{gr} / \mathrm{L}$. All media contained ampicillin at $100 \mu \mathrm{g} / \mathrm{mL}$.

\subsection{Bacterial Growth}

Escherichia coli DH10B bacteria bearing or lacking (as a reference) the viral chimera were grown overnight in $\mathrm{LB}$ at $37^{\circ} \mathrm{C}$. Thereafter, the growth culture was diluted and the bacteria were grown until their O.D. 600 reached 0.2. Subsequently, $50 \mu \mathrm{L}$ of bacterial culture was dispensed into 96-well flat-bottomed plates (Nunc, Roskilde, Denmark) containing $50 \mu \mathrm{L}$ of the different treatments. Unless stated otherwise, IPTG was added to the cells to final concentrations ranging from 0 to $100 \mu \mathrm{M}$. D-glucose was added to a concentration of $1 \%$. Moreover, 96-well plates were incubated for $16 \mathrm{~h}$ at $37^{\circ} \mathrm{C}$ in an Infinite 200 from the Tecan Group (Männedorf, Switzerland) at a constant high shaking rate. O.D.600 readings were recorded every $15 \mathrm{~min}$. For every measurement, duplicates or triplicates were conducted.

For the Escherichia coli LB650 bacteria, the same protocol was used, except that growth was done in LBK overnight. Subsequently, the bacteria were diluted and grown until their O.D.600 reached 0.2, after which the media was replaced to LB and diluted twofold with the various treatments in each well. Unless stated otherwise, IPTG was added to the LB650 bacteria to a final concentration of $10 \mu \mathrm{M}$.

\subsection{Maltose Complementation Assay}

All selected viroporin chimera were transformed into NT326 bacteria. Transformed cells were cultured on M9 minimal medium plates containing $0.4 \%$ maltose as the only carbon source, $1 \%$ Bacto agar (Difco, MD), and $100 \mu \mathrm{M}$ IPTG for three days at $37^{\circ} \mathrm{C}$. Transformed cells expressing MBP (unfused to any viral gene) were used as a control.

\section{8. pHlux Assay}

Transformed LR1 cells with different viroporin chimera were cultured overnight in LB media containing $1 \%$ glucose and $100 \mu \mathrm{M}$ ampicillin. Secondary cultures were prepared by diluting the primary culture by 1:500 in LB media and allowing it to grow up to an O.D. ${ }_{600}$ of 0.6-0.8. Viroporin synthesis was induced by the addition of $50 \mu \mathrm{M}$ IPTG for one hour. Cultures without IPTG induction were used as control. Following one hour of induction, the O.D.600 of all cells were measured, and after pelleting at $3500 \mathrm{~g}$ for $10 \mathrm{~min}$, the bacteria were resuspended in Mcllvaine buffer $(200 \mathrm{mM}$ 
$\mathrm{Na}_{2} \mathrm{HPO}_{4}, 0.9 \% \mathrm{NaCl}$ adjusted to $\mathrm{pH} 7.6$ with $0.1 \mathrm{M}$ citric acid, $0.9 \% \mathrm{Nacl}$ ) to an optical density of 0.25 at $600 \mathrm{~nm}$. Subsequently, $200 \mu \mathrm{L}$ of cell suspension were transferred with $30 \mu \mathrm{L}$ of McIlvaine buffer to a 96-well plate. The plate included a row with only an assay buffer and cultures without induction. The fluorescence measurements were carried out in a microplate reader (Infinite F200 pro, Tecan). The plate reader was set with two pairs of bandpass filters: A $520 \mathrm{~nm}$ emission filter combined with $390 \mathrm{~nm}$ and $466 \mathrm{~nm}$ excitation filters. A liquid handling system (Tecan) was used to add $70 \mu \mathrm{L}$ of $300 \mathrm{mM}$ citric acid with $0.9 \% \mathrm{NaCl}$ to the bacteria. The fluorescence emission of each well after the addition of acid was measured by alternate read out of the two filter pairs for $30 \mathrm{~s}$. The ratio for the two differently excited emissions, $\mathcal{F}=F_{390} \mathrm{~nm} / F_{466} \mathrm{~nm}$ was calculated and translated into proton concentration using the following equation according to [46,47]:

$$
\left[\mathrm{H}^{+}\right]=0.132 \cdot \mathcal{F}^{-1.75 \cdot \mathcal{F}^{0.51}}
$$

\subsection{Experimental Controls}

Two controls were used in order to gauge the activity of the viroporin chimera: The first control involved the unadulterated pMAL-p2X plasmid (New England Biolabs, Ipswich, MA, USA) in which MBP is not fused to any protein at its carboxy terminus. The second control was one in which MBP was fused at its carboxy terminus to a "generic" transmembrane domain. Specifically, we placed the transmembrane domain of human glycophorin A (residues Glu70—Leu98) containing two monomerizing mutations: Gly79Ile and Gly83Ile [48,49].

\section{Results}

\subsection{Sequence Analysis}

In order to identify potential viroporins, we utilized characteristic features of the viroporin family, as exemplified by the M2 proteins from influenza A, B, and C strains $[10,17,50]$, and many other viruses [1-6]. Specifically, we searched for small (less than 100 residues) membrane proteins in genomes of the following enveloped viruses: Eastern equine encephalitis (EEE) virus, West Nile virus, Dengue virus, and Variola virus. These viruses represent important biomedical threats, and as such, any new drug target that is identified in their genomes may be of potential use. Using Phobius, a combined transmembrane topology and signal peptide predictor [39,40], we found six viroporin candidates listed in Table 1 and shown schematically in Figure 1 according to their predicted topology. Analyses employing TMpred [41] and MEMSAT [42] algorithms yielded similar results, with the exception of EEEV 6k protein, which was not identified as membranous by MEMSAT (see Table 2). Of the six proteins, EEE virus $6 \mathrm{k}$ is similar to homologous proteins from other alphaviruses that have been shown to possess ion channel activity, such as Sindbis virus [51], Ross River virus, Barmah Forest virus [52], and Semliki forest virus [53]. Similarly, a synthetic peptide that corresponds to part of the Dengue virus $\mathrm{Mg}$ protein has been shown to possess channel activity [54].

Table 1. List of candidate viroporins analyzed in the current study. The sequences and topologies of the proteins according to Phobius $[39,40]$ are shown in Figure 1. EEE is Eastern equine encephalitis.

\begin{tabular}{cccc}
\hline Virus & Protein & Accession No. & Length \\
\hline EEE virus & 6k protein & AMN91461.1 & 57 \\
West Nile virus & Membrane glycoprotein M (MgM) & YP_001527877.1 & 75 \\
Dengue virus 1 & Membrane glycoprotein $(\mathrm{Mg})$ & NP_722459.2 & 75 \\
Dengue virus 1 & 2k Protein & NP_722467.1 & 24 \\
Variola virus & gp151 & NP_042195.1 & 61 \\
Variola virus & gp170 & NP_042214.1 & 66 \\
\hline
\end{tabular}


Table 2. Transmembrane segment prediction of the candidate viroporins analyzed in the current study. See Table 1 for complete names of proteins and accession numbers. All programs were run with default values.

\begin{tabular}{cccc}
\hline Proteins & Phobious [39,40] & TMpred [41] & MEMSAT [42] \\
\hline EEEV 6k protein & $17-33 ; 38-56$ & $16-37 ; 38-57$ & No TM detected \\
WNV MgM & $42-70$ & $42-75$ & $41-58$ \\
DV Mg & $44-70$ & $41-75$ & $44-68$ \\
DV 2k & $6-23$ & $8-24$ & Too short for prediction \\
VV gp151 & $12-32$ & $12-32$ & $12-32$ \\
VV gp170 & $30-57$ & $39-57$ & $39-57$ \\
\hline
\end{tabular}

When comparing the sequences of the different putative viroporins, no appreciable similarities were detected. The only exception was between the two flaviviruses-West Nile virus MgM and Dengue virus Mg proteins (Table 3).

Table 3. Pairwise comparisons (E-values) between the candidate viroporins analyzed in the current study. Comparisons were conducted with the blasptp algorithm [55], using default values, whereby the protein in the column was used as a reference. A "-" sign designates that the program was unable to find a significant similarity between the sequences, while a black cell indicates self-similarity. See Table 1 for complete names of proteins and accession numbers.

\begin{tabular}{ccccccc}
\hline & 6k & MgM & Mg & 2k & gp151 & gp170 \\
\hline 6k & & 0.077 & 2.9 & 4.5 & - & 0.75 \\
MgM & 0.031 & & $3 \times 10^{-10}$ & 0.32 & - & - \\
Mg & 2.9 & $10^{-14}$ & & 4.3 & - & - \\
2k & - & - & - & & - & - \\
gp151 & - & - & - & - & & - \\
gp170 & 0.75 & - & - & 0.003 & - & \\
\hline
\end{tabular}

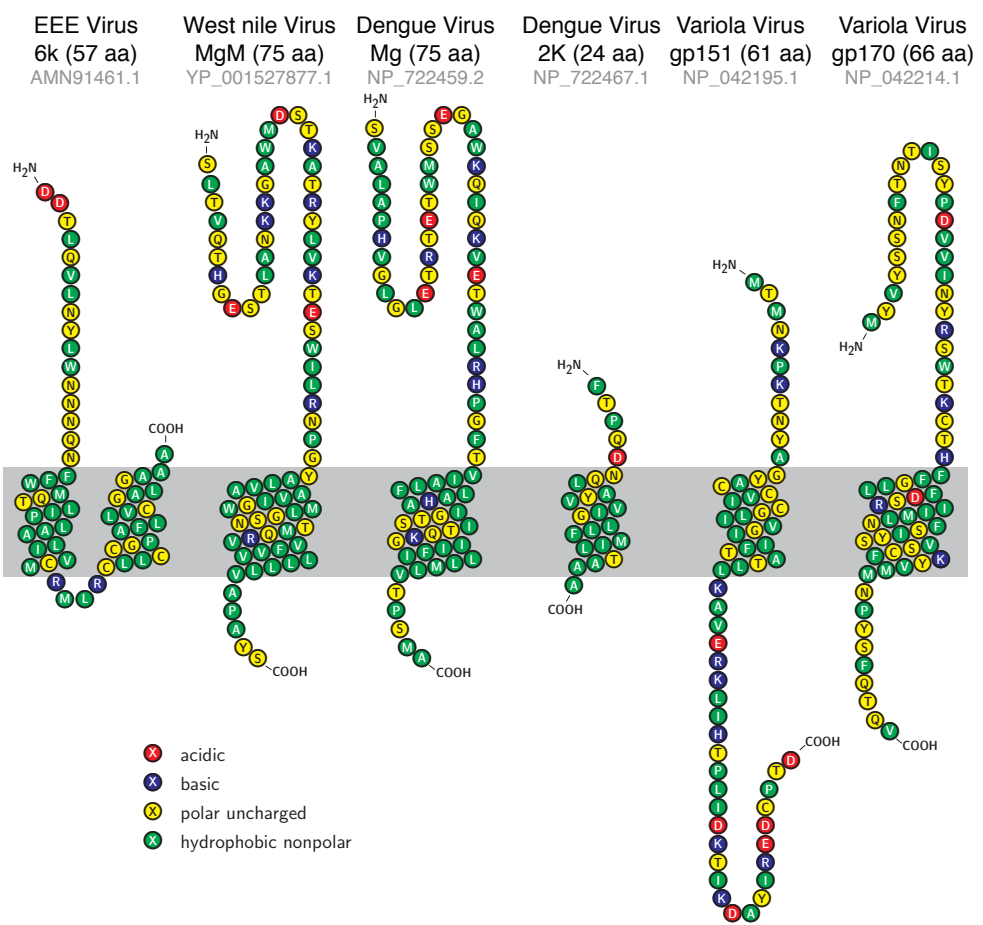

Figure 1. Sequence and topology of candidate viroporins. Sequences of the proteins analyzed in the current study alongside their predicted topologies according to Phobius [39,40]. The shaded region indicates the presumed position of the lipid bilayer. The lengths of the proteins are stated in the parentheses and the accession numbers in gray. The figure was prepared using $\mathrm{T}_{\mathrm{E}} \mathrm{X}$ topo version 1.5 [56]. 


\subsection{Expression and Membrane Incorporation}

We next proceeded to express the proteins in several bacterial hosts in order to evaluate their ion channel activity. In an effort to ensure that the proteins are incorporated in the inner membrane of the bacteria, we constructed chimeras as follows: The amino-termini of the viral proteins were fused to the carboxy-terminus of the maltose binding protein (MBP) employing the pMAL ${ }^{\text {TM }}$ Protein Fusion and Purification System from New England Biolabs. Note that MBP is monomeric, and as such does not induce oligomerization [57]. The secretion was subsequently directed by the signal peptide of MBP, placing the amino terminus of the viral protein in the bacterial periplasm. Similar constructs were shown to be successful with other viroporins such as Influenza M2 [58-60] and HIV vpu [61]. Finally, membrane incorporation could be confirmed using a genetic screen upon expression of the chimera in malE- bacteria. These bacteria are incapable of growing when maltose is the only carbon source since they lack a native MBP in the periplasm [62].

As shown in Figure 2, the expression of all chimeras was able to sustain bacterial growth when maltose was the only carbon source. In contrast, bacteria that did not express an MBP chimera were nonviable under these conditions. In conclusion, these findings demonstrate that all the viral proteins were inserted in the periplasmic membrane of the bacteria such that their $\mathrm{N}$-termini are in the periplasm.

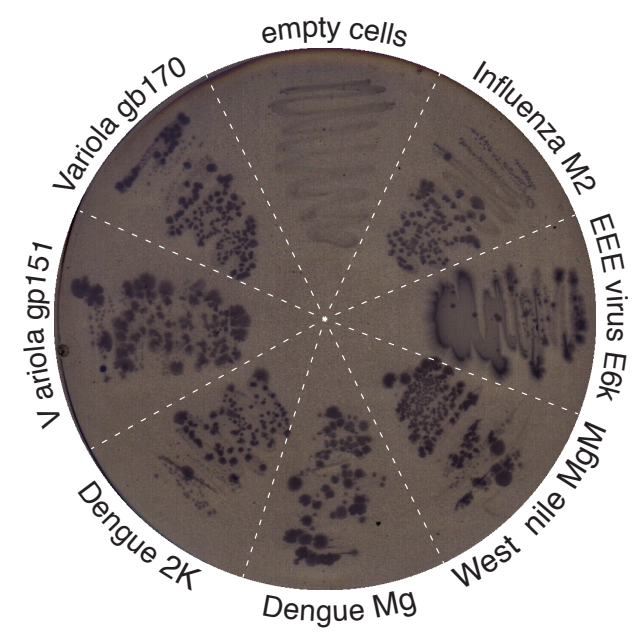

Figure 2. Membrane incorporation assay. Test for proper insertion and orientation of viral chimera based on the malE $^{-}$complementation assay [62]. Bacteria lacking any maltose binding protein (MBP) were transformed with various viroporins which were fused to MBP and cultivated on M9 agar containing $0.4 \%$ maltose and $10 \mu \mathrm{M}$ isopropyl $\beta$-D-1-thiogalactopyranoside (IPTG).

\subsection{Positive Genetic Test}

We have previously developed a genetic selection capable of examining the ability of a particular protein to conduct $\mathrm{K}^{+}[60,61]$. The assay is based on the inability of $\mathrm{K}^{+}$-uptake-deficient bacteria [43] to grow on media containing low concentrations of potassium. However, when the bacteria express a protein capable of $\mathrm{K}^{+}$transport, they are suddenly able to thrive under low $\mathrm{K}^{+}$conditions.

Results shown in Figure 3 demonstrate appreciable growth enhancement in bacteria that harbor viral chimeras. For example, the expression of the Dengue virus $2 \mathrm{~K}$ and $\mathrm{Mg} 1$ chimeras increases the growth rates of the bacteria by $273 \%$ and $57 \%$, respectively. Furthermore, in several instances, increasing the expression of the chimeric proteins beyond basal levels (by adding the inducer IPTG), enhances the growth rate appreciably. In other instances, the basal level expression is sufficient to beneficially impact bacterial growth. As a control, bacteria that express MBP or MBP fused to a generic transmembrane domain do not exhibit appreciable growth enhancement. Taken together, all the viral proteins are capable of supporting $\mathrm{K}^{+}$transport in the assay employed. 


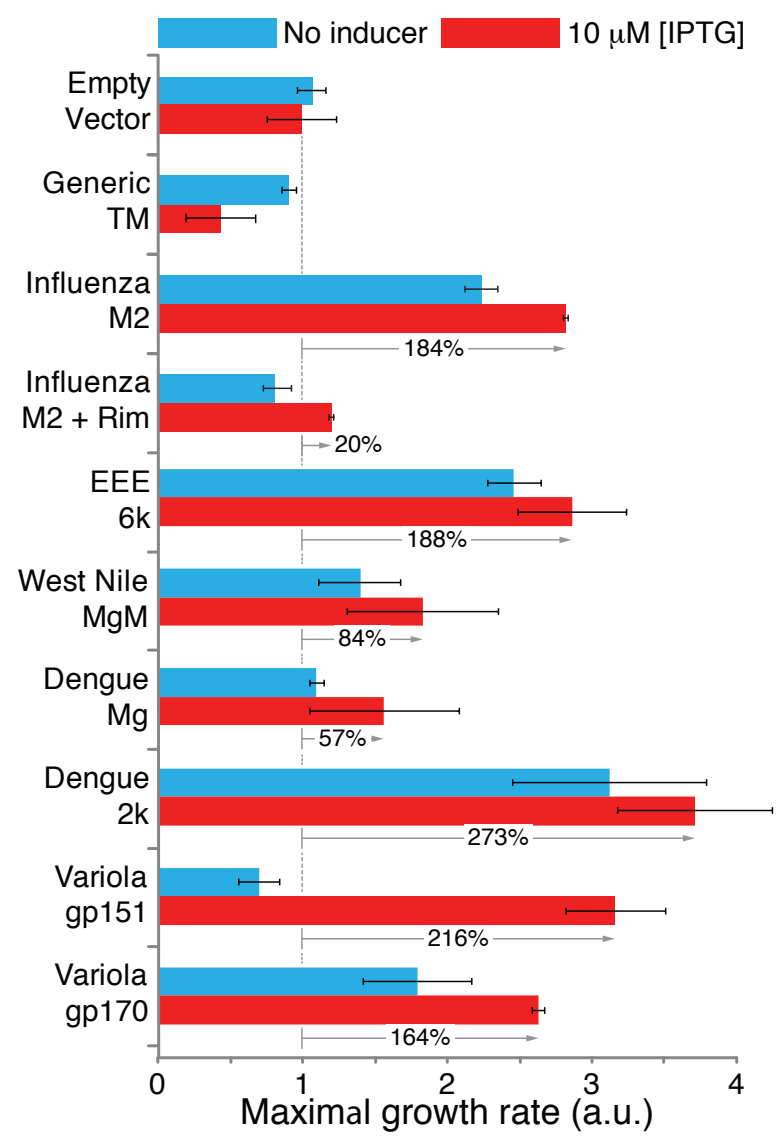

Figure 3. Positive genetic test for viroporin activity. Impact of viral protein expression on the growth of $\mathrm{K}^{+}$-uptake-deficient bacteria [43]. The relative growth enhancements in comparison to bacteria that harbor an empty vector (MBP on its own) are indicated by the gray arrows. Generic TM indicates a chimera in which MBP is fused at its carboxy terminus to the transmembrane domain of glycophorin A containing two monomerizing mutations [48,49]. M2 + Rim is a sample in which rimantadine, a specific blocker of the influenza M2 channel [10], was added at a concentration of $50 \mu \mathrm{M}$. Note that rimantadine did not affect other proteins (data not shown). The results are an average of three independent experiments, with standard deviations depicted as error bars.

\subsection{Negative Genetic Test}

In complementary fashion to the positive genetic test detailed above, we have devised a genetic selection in which channel formation is detrimental to bacteria [58]. In this instance, the chimeric protein is expressed at elevated levels in "regular" Escherichia coli. This results in appreciable growth retardation, presumably due to extensive membrane permeabilization. This particular assay has the additional benefit that it may be used to search for blockers that mitigate the deleterious effect of the viral channel [59].

Figure 4 depicts the results of the negative genetic assay of the various chimeras. The growth rates of bacteria that harbor various vectors are analyzed as a function of the concentration of the expression inducer (IPTG). Bacteria that harbor a vector that contains only MBP do not exhibit appreciable growth retardation when protein induction is increased. Similarly, bacteria that express a chimera in which a generic transmembrane domain is fused to MBP, do not exhibit any reduction in growth rates as a function of inducer concentration. In contrast, substantial growth impairment is observed when the bacteria express viral chimera. For example, increasing the IPTG concentration to $100 \mu \mathrm{M}$ lowers the maximal growth rate by $81 \%$ in bacteria that express the Eastern equine encephalitis virus $6 \mathrm{k}$ protein. The only exception is bacteria that express the Dengue virus $2 \mathrm{k}$ protein, which exhibits only an $18 \%$ growth reduction. 


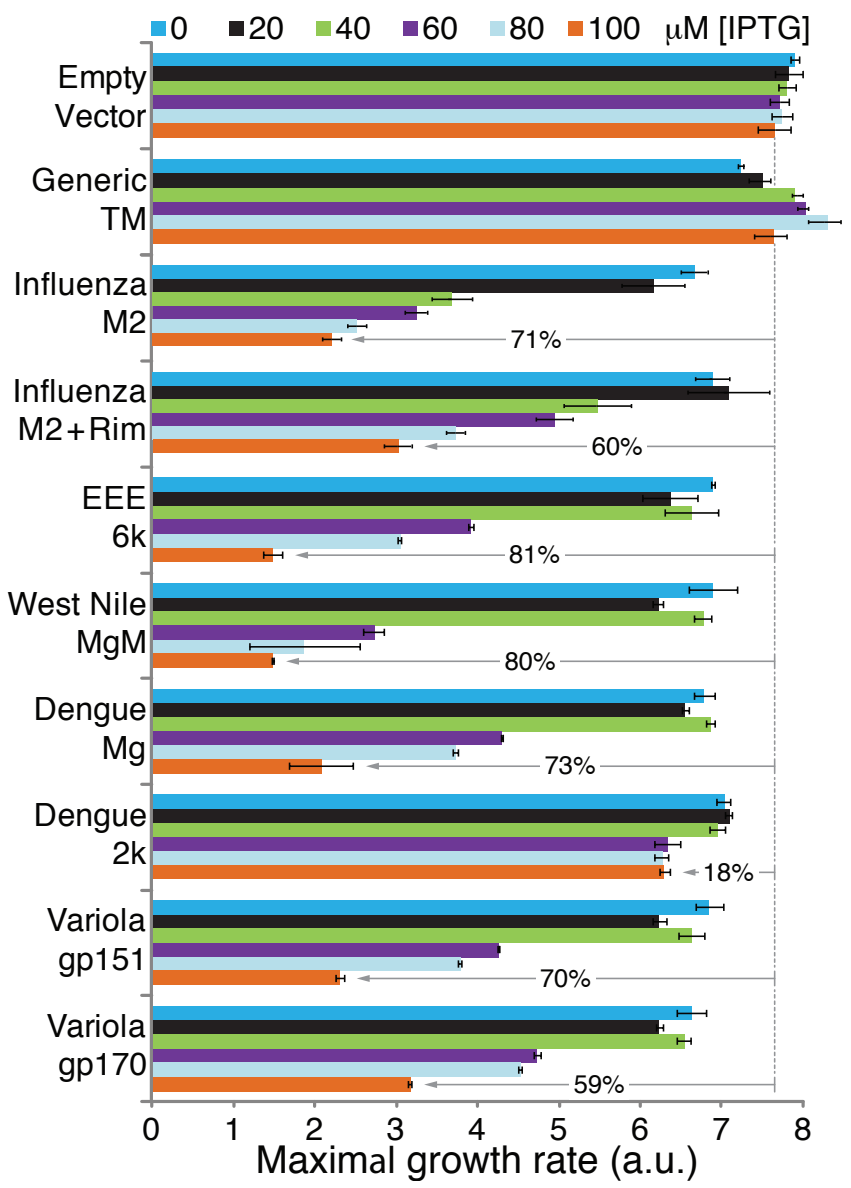

Figure 4. Negative genetic test for viroporin activity. The impact of viral protein expression on bacterial growth as a function of the concentration of the inducer IPTG varied between 0 to $100 \mu \mathrm{M}$, as indicated. The relative growth inhibitions in comparison to bacteria that harbor an empty vector (MBP on its own) are indicated by the gray arrows. Generic TM indicates a chimera in which MBP is fused at its carboxy terminus to the transmembrane domain of glycophorin A containing two monomerizing mutations [48,49]. M2 + Rim is a sample in which rimantadine, a specific blocker of the influenza M2 channel [10], was added at a concentration of $50 \mu \mathrm{M}$. Note that rimantadine did not affect other proteins (data not shown). The results are an average of three independent experiments, with standard deviations depicted as error bars.

\subsection{Proton Flux}

The final bacterial assay that was used measured $\mathrm{H}^{+}$conductivity. Bacteria that constitutively express a $\mathrm{pH}$-sensitive green fluorescent protein - $\mathrm{pHluorin}$ [44], can be used to analyze the membrane permeation to $\mathrm{H}^{+} \mathrm{s}[46,47]$. Specifically, the emission at $520 \mathrm{~nm}$ of pHluorin has two excitation maxima: $390 \mathrm{~nm}$ and $466 \mathrm{~nm}$, whose ratio changes as a function of $\mathrm{pH}$ [44]. Consequently, using a calibration curve enables one to relate the fluorescent quotient directly to the $\mathrm{H}^{+}$concentration $[46,47]$.

Experimentally, we monitored the fluorescence obtained when exciting at $390 \mathrm{~nm}$ and $466 \mathrm{~nm}$ upon injection of a concentrated acid solution to the buffer. Any bacteria that express an $\mathrm{H}^{+}$-conducting channel will exhibit a dramatic change in the fluorescence ratio in contrast to control bacteria that contain an empty vector.

As shown in Figure 5, bacteria that do not express a viral protein exhibited only a minor $\mathrm{pH}$ drop, from 6.31 to 6.27. Similarly, no drop in $\mathrm{pH}$ was observed in bacteria that express a chimera between $\mathrm{MBP}$ and a generic transmembrane domain. In contrast, as a positive control, bacteria that express the influenza virus $\mathrm{M} 2$ protein, a well-characterized $\mathrm{H}^{+}$channel [10], exhibited a substantial increase in acidity of $\Delta \mathrm{pH}=0.62$. 

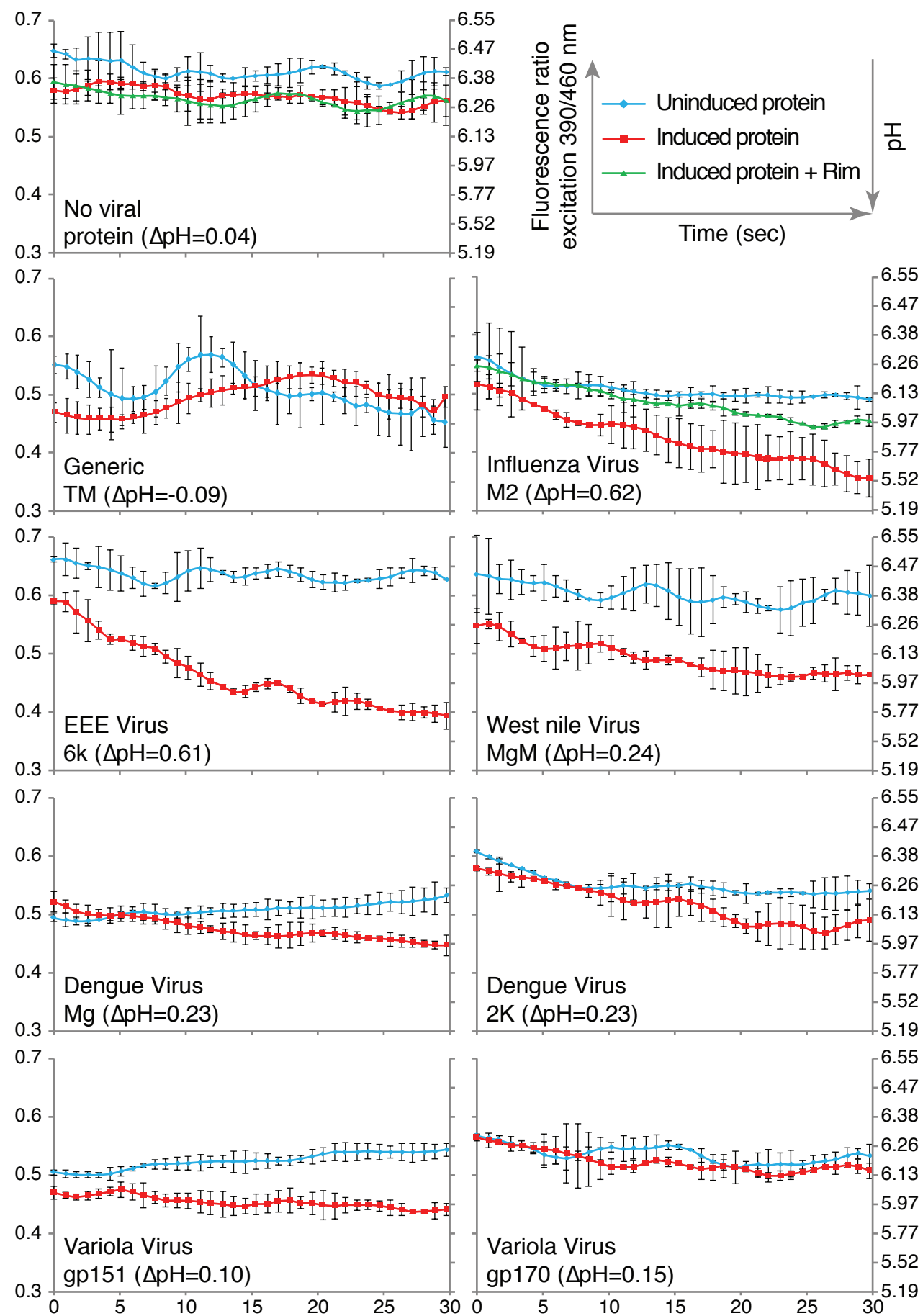

Figure 5. Fluorescence-based $\mathrm{H}^{+}$conductivity assay. The fluorescence of bacteria that harbor pHluorin, a $\mathrm{pH}$-sensitive green fluorescence protein (GFP) [44], was examined as a function of the expressed viral chimera [46,47]. Protein levels were governed by the level of the inducer (50 $\mu \mathrm{M}$ IPTG), as indicated. At time 0, a concentrated acid solution was injected into the media. Consequently, a drop of the fluorescence ratio between excitation at $390 \mathrm{~nm}$ relative to excitation at $466 \mathrm{~nm}$ (shown on the left axis) is indicative of a $\mathrm{pH}$ decrease, as shown on the right axis. The $\Delta \mathrm{pH}$ values indicated in the parentheses correspond to the difference in the $\mathrm{pH}$ after $30 \mathrm{~s}$ in bacteria that had undergone protein induction. Generic TM indicates a chimera in which MBP is fused at its carboxy terminus to the transmembrane domain of glycophorin A containing two monomerizing mutations [48,49]. + Rim is a sample in which rimantadine, a specific blocker of the influenza M2 channel [10], was added at a concentration of $50 \mu \mathrm{M}$. Note that rimantadine did not affect other proteins (data not shown). The results are an average of three independent experiments, with standard deviations depicted as error bars. 
All viral proteins exhibited acidity increases that were larger than the negative controls (i.e., MBP or MBP fused to a generic transmembrane domain), albeit at different levels. For example, the expression of Eastern equine encephalitis virus $6 \mathrm{k}$ protein resulted in a large acidity drop of $\Delta \mathrm{pH}=0.61$, while Variola virus gp151 resulted in only a small $\mathrm{pH}$ drop of 0.1 units. Finally, we note that minor differences in $\mathrm{pH}$ starting points may reflect experimental variability in growth conditions and potentially basal expression levels of the viral chimera.

\section{Discussion}

The goal of this study was to identify potential ion channels from biomedically important viruses. Scanning the genomes of Variola, Dengue, West Nile, and Eastern equine encephalitis viruses resulted in the identification of several candidate proteins that were less than one hundred amino acids in length and contained one or more putative transmembrane segments. The shortest open reading frame was Dengue virus $2 \mathrm{~K}$ protein with 24 amino acids, while the longest was West Nile virus MgM and Dengue virus Mg1, each with 75 amino acids (see Figure 1). No similarities were observed between the different viroporin sequences, other than that observed between the two falvivirus proteins (Table 3). The reason for this finding might be that viroporins were not selected in the course of evolution to exhibit precise conductivity characteristics, as the channels in the neuromuscular system. Therefore, the sequence requirements for simple conductivity allow for great variation in sequence. Finally, as these features are all indicative of viroporins [1-6], we decided to examine the functionally of the proteins in three different bacterial assays.

Prior to any conductivity tests, it was important to ensure expression and membrane incorporation in bacteria. To that end, we constructed chimeric proteins in which the different viral proteins were attached to the carboxy terminus of the maltose binding protein (MBP). In such constructs, MBP, due to its leader peptide, would cause the chimera to be targeted to the periplasm causing the viroporin to traverse the inner bacterial membrane with its amino terminus in the periplasm. malE complementation assay [62] did indeed reveal that all proteins were targeted to the inner membrane of the bacteria (Figure 2).

Following confirmation of membrane incorporation of the various proteins, we could analyze their potential conductivity using three independent assays. In the first assay, any protein that was capable of potassium transport could revive the growth of $\mathrm{K}^{+}$-uptake-deficient bacteria [43]. In the second assay, the chimeric proteins were expressed at varying levels in bacteria and their deleterious impact upon growth, due to excess membrane permeabilization, was monitored. The final test that was used measured $\mathrm{H}^{+}$conductivity using a $\mathrm{pH}$-sensitive green fluorescent protein called pHluorin [44].

All of these assays had already been tested before on the best-characterized viroporin-the M2 channel from Influenza A [46,47,58-60]. This particular channel has the advantage that it has an effective blocker that can negate its channel activity [10], thereby demonstrating the assays' specificity. Therefore, the results of examining the M2 channel, in these three assays, in the presence or absence of its specific inhibitor, are presented as controls. Finally, two additional negative controls are utilized: MBP fused to a generic transmembrane domain and $\mathrm{MBP}$ on its own.

All of the viral proteins scored positively (above control) in the three bacterial assays, albeit at different levels. Since the different bacterial assays test non-identical characteristics of the proteins, they should be used in concert in order to predict channel activity. Hence, we may conclude that all of the aforementioned proteins may be classified as potential viroporin candidates, open for future detailed investigation. Moreover, the approach that we have taken can be readily employed to examine numerous other open reading frames, yielding additional targets for research.

Amongst future studies of the candidate proteins, one may mention the detailed characterization of the channel activity by approaches such as patch clamping. In addition, it is important to ascertain the relevance of the conductivity of these proteins to their cognate viruses. If their channel activities are shown to be essential for viral infectivity, the negative assay used in their identification (Figure 4) may be used to search for blockers. Such inhibitors could be classified as potential new anti-viral agents, as was done for other viroporins [59]. 
Author Contributions: Conceptualization, I.T.A.; methodology, P.P.S.T., R.O., and M.K.; formal analysis, I.T.A., P.P.S.T., R.O., and M.K.; investigation, P.P.S.T., R.O., and M.K.; resources, I.T.A; writing—original draft preparation, I.T.A.; writing-review and editing, I.T.A.; visualization, I.T.A., P.P.S.T., and R.O.; supervision, I.T.A.; project administration, I.T.A.; funding acquisition, I.T.A.

Funding: This work was supported in part by grants from the the binational science foundation, the Israeli Science Foundation, and the Israeli Science Ministry. I.T.A. is the Arthur Lejwa Professor of Structural Biochemistry at the Hebrew University of Jerusalem.

Acknowledgments: The authors wish to thank M. Willemoës and K. Lindorff-Larsen from the University of Copenhagen for their assistance with the pHlux assay.

Conflicts of Interest: The authors declare no conflict of interest.

\section{Abbreviations}

The following abbreviations are used in this manuscript:

EEE Eastern equine encephalitis

MBP Maltose binding protein

HIV Human immunodeficiency virus

IPTG isopropyl $\beta$-D-1-thiogalactopyranoside

LB Lysogeny Broth

LBK Lysogeny Broth in which $\mathrm{Na}^{+}$is substituted by $\mathrm{K}^{+}$

TM Transmembrane

\section{References}

1. Gonzalez, M.E.; Carrasco, L. Viroporins. FEBS Lett. 2003, 552, 28-34. [CrossRef]

2. DiMaio, D. Viral Miniproteins. Annu. Rev. Microbiol. 2014, 68, 21-43. [CrossRef] [PubMed]

3. Fung, T.S.; Torres, J.; Liu, D.X. The Emerging Roles of Viroporins in ER Stress Response and Autophagy Induction During Virus Infection. Viruses 2015, 7, 2834-2857. [CrossRef] [PubMed]

4. Sze, C.W.; Tan, Y.J. Viral Membrane Channels: Role and Function in the Virus Life Cycle. Viruses 2015, 7, 3261-3284. [CrossRef] [PubMed]

5. Royle, J.; Dobson, S.J.; Müller, M.; Macdonald, A. Emerging Roles of Viroporins Encoded by DNA Viruses: Novel Targets for Antivirals? Viruses 2015, 7, 5375-5387. [CrossRef] [PubMed]

6. To, J.; Surya, W.; Torres, J. Targeting the Channel Activity of Viroporins. Adv. Protein Chem. Struct. Biol. 2016, 104, 307-355. [PubMed]

7. Lamb, R.A.; Lai, C.J. Conservation of the Influenza Virus Membrane Protein (M1) Amino Acid Sequence and an Open Reading Frame of RNA Segment 7 Encoding a Second Protein (M2) in H1N1 and H3N2 Strains. Virology 1981, 112, 746-751. [CrossRef]

8. Lamb, R.A.; Choppin, P.W. Identification of a Second Protein (M2) Encoded by RNA Segment 7 of Influenza Virus. Virology 1981, 112, 729-737. [CrossRef]

9. Hay, A.J.; Wolstenholme, A.J.; Skehel, J.J.; Smith, M.H. The Molecular Basis of the Specific Anti-Influenza Action of Amantadine. EMBO J. 1985, 4, 3021-3024. [CrossRef] [PubMed]

10. Pinto, L.H.; Holsinger, L.J.; Lamb, R.A. Influenza Virus M2 Protein Has Ion Channel Activity. Cell 1992, 69, 517-528. [CrossRef]

11. Holsinger, L.J.; Lamb, R.A. Influenza Virus M2 Integral Membrane Protein Is a Homotetramer Stabilized by Formation of Disulfide Bonds. Virology 1991, 183, 32-43. [CrossRef]

12. Stouffer, A.L.; Acharya, R.; Salom, D.; Levine, A.S.; Di Costanzo, L.; Soto, C.S.; Tereshko, V.; Nanda, V.; Stayrook, S.; DeGrado, W.F. Structural Basis for the Function and Inhibition of an Influenza Virus Proton Channel. Nature 2008, 451, 596-599. [CrossRef] [PubMed]

13. Schnell, J.R.; Chou, J.J. Structure and Mechanism of the M2 Proton Channel of Influenza a Virus. Nature 2008, 451, 591-595. [CrossRef] [PubMed]

14. Sharma, M.; Yi, M.; Dong, H.; Qin, H.; Peterson, E.; Busath, D.D.; Zhou, H.X.; Cross, T.A. Insight Into the Mechanism of the Influenza a Proton Channel From a Structure in a Lipid Bilayer. Science 2010, 330, 509-512. [CrossRef] [PubMed] 
15. Paterson, R.G.; Takeda, M.; Ohigashi, Y.; Pinto, L.H.; Lamb, R.A. Influenza B Virus BM2 Protein Is an Oligomeric Integral Membrane Protein Expressed at the Cell Surface. Virology 2003, 306, 7-17. [CrossRef]

16. Horvath, C.M.; Williams, M.A.; Lamb, R.A. Eukaryotic Coupled Translation of Tandem Cistrons: Identification of the Influenza B Virus BM2 Polypeptide. EMBO J. 1990, 9, 2639-2647. [CrossRef] [PubMed]

17. Hongo, S.; Ishii, K.; Mori, K.; Takashita, E.; Muraki, Y.; Matsuzaki, Y.; Sugawara, K. Detection of ion channel activity in Xenopus laevis oocytes expressing Influenza C virus CM2 protein. Arch. Virol. 2004, 149, 35-50. [CrossRef]

18. Hongo, S.; Sugawara, K.; Nishimura, H.; Muraki, Y.; Kitame, F.; Nakamura, K. Identification of a Second Protein Encoded by Influenza C Virus RNA Segment 6. J. Gen. Virol. 1994, 75 Pt 12, 3503-3510. [CrossRef]

19. Schubert, U.; Ferrer-Montiel, A.V.; Oblatt-Montal, M.; Henklein, P.; Strebel, K.; Montal, M. Identification of an Ion Channel Activity of the Vpu Transmembrane Domain and Its Involvement in the Regulation of Virus Release From HIV-1-Infected Cells. FEBS Lett. 1996, 398, 12-18. [CrossRef]

20. Strebel, K.; Klimkait, T.; Martin, M.A. A Novel Gene of HIV-1, Vpu, and Its 16-Kilodalton Product. Science 1988, 241, 1221-1223. [CrossRef]

21. Cohen, E.A.; Terwilliger, E.F.; Sodroski, J.G.; Haseltine, W.A. Identification of a Protein Encoded by the Vpu Gene of HIV-1. Nature 1988, 334, 532-534. [CrossRef] [PubMed]

22. Griffin, S.D.C.; Beales, L.P.; Clarke, D.S.; Worsfold, O.; Evans, S.D.; Jaeger, J.; Harris, M.P.G.; Rowlands, D.J. The p7 Protein of Hepatitis C Virus Forms an Ion Channel That Is Blocked by the Antiviral Drug, Amantadine. FEBS Lett. 2003, 535, 34-38. [CrossRef]

23. Lin, C.; Lindenbach, B.D.; Prágai, B.M.; McCourt, D.W.; Rice, C.M. Processing in the Hepatitis C Virus E2-NS2 Region: Identification of $\mathrm{p} 7$ and Two Distinct E2-Specific Products with Different C Termini. J. Virol. 1994, 68, 5063-5073. [PubMed]

24. He, J.; Melnik, L.I.; Komin, A.; Wiedman, G.; Fuselier, T.; Morris, C.F.; Starr, C.G.; Searson, P.C.; Gallaher, W.R.; Hristova, K.; et al. Ebola Virus Delta Peptide is a Viroporin. J. Virol. 2017, 91, e00438-17. [CrossRef] [PubMed]

25. Chang, Y.S.; Liao, C.L.; Tsao, C.H.; Chen, M.C.; Liu, C.I.; Chen, L.K.; Lin, Y.L. Membrane permeabilization by small hydrophobic nonstructural proteins of Japanese encephalitis virus. J. Virol. 1999, 73, 6257-6264. [PubMed]

26. León-Juárez, M.; Martínez-Castillo, M.; Shrivastava, G.; García-Cordero, J.; Villegas-Sepulveda, N.; Mondragón-Castelán, M.; Mondragón-Flores, R.; Cedillo-Barrón, L. Recombinant Dengue virus protein NS2B alters membrane permeability in different membrane models. Virol. J. 2016, 13, 1. [CrossRef]

27. Han, Z.; Harty, R.N. The NS3 protein of bluetongue virus exhibits viroporin-like properties. J. Biol. Chem. 2004, 279, 43092-43097. [CrossRef]

28. Gan, S.W.; Ng, L.; Lin, X.; Gong, X.; Torres, J. Structure and Ion Channel Activity of the Human Respiratory Syncytial Virus (hRSV) Small Hydrophobic Protein Transmembrane Domain. Protein Sci. 2008, 17, 813-820. [CrossRef]

29. Collins, P.L.; Olmsted, R.A.; Johnson, P.R. The Small Hydrophobic Protein of Human Respiratory Syncytial Virus: Comparison Between Antigenic Subgroups a and B. J. Gen. Virol. 1990, 71 Pt 7, 1571-1576. [CrossRef]

30. Strebel, K. HIV-1 Vpu - an Ion Channel in Search of a Job. Biochim. Biophys. Acta 2014, 1838, $1074-1081$. [CrossRef]

31. Rosenberg, M.R.; Weaver, L.M.; Casarotto, M.G. Probing Interactions of Vpu From HIV-1 with Amiloride-Based Compounds. Biochim. Biophys. Acta 2016, 1858, 733-739. [CrossRef] [PubMed]

32. Pavlović, D.; Neville, D.C.; Argaud, O.; Blumberg, B.; Dwek, R.A.; Fischer, W.B.; Zitzmann, N. The Hepatitis C Virus $\mathrm{p} 7$ Protein Forms an Ion Channel That Is Inhibited by Long-Alkyl-Chain Iminosugar Derivatives. Proc. Natl. Acad. Sci. USA 2003, 100, 6104-6108.

33. Luscombe, C.A.; Huang, Z.; Murray, M.G.; Miller, M.; Wilkinson, J.; Ewart, G.D. A Novel Hepatitis C Virus p7 Ion Channel Inhibitor, BIT225, Inhibits Bovine Viral Diarrhea Virus in Vitro and Shows Synergism with Recombinant Interferon-Alpha-2b and Nucleoside Analogues. Antivir. Res. 2010, 86, 144-153. [CrossRef] [PubMed]

34. Rey-Carrizo, M.; Torres, E.; Ma, C.; Barniol-Xicota, M.; Wang, J.; Wu, Y.; Naesens, L.; DeGrado, W.F.; Lamb, R.A.; Pinto, L.H.; et al. 3-Azatetracyclo[5.2.1.1(5,8).0(1,5)]Undecane Derivatives: From Wild-Type Inhibitors of the M2 Ion Channel of Influenza a Virus to Derivatives with Potent Activity Against the V27A Mutant. J. Med. Chem. 2013, 56, 9265-9274. [CrossRef] [PubMed] 
35. Wang, J.; Cady, S.D.; Balannik, V.; Pinto, L.H.; DeGrado, W.F.; Hong, M. Discovery of Spiro-Piperidine Inhibitors and Their Modulation of the Dynamics of the M2 Proton Channel From Influenza a Virus. J. Am. Chem. Soc. 2009, 131, 8066-8076. [CrossRef] [PubMed]

36. Griffin, D.E. Fields Virology; Wolters Kluwer: Philadelphia, PA, USA, 2013; Chapter 23.

37. Pierson, T.C.; Diamond, M.S. Fields Virology; Wolters Kluwer: Philadelphia, PA, USA, 2013; Chapter 26.

38. Moss, B. Fields Virology; Wolters Kluwer: Philadelphia, PA, USA, 2013; Chapter 66.

39. Käll, L.; Krogh, A.; Sonnhammer, E. L Advantages of Combined Transmembrane Topology and Signal Peptide Prediction-The Phobius Web Server. Nucleic Acids Res. 2007, 35, W429-W432. [CrossRef] [PubMed]

40. Käll, L.; Krogh, A.; Sonnhammer, E.L. A Combined Transmembrane Topology and Signal Peptide Prediction Method. J. Mol. Biol. 2004, 338, 1027-1036. [CrossRef] [PubMed]

41. Hofmann, K.; Stoffel, W. TMbase-A database of membrane spanning proteins segments. Biol. Chem. Hoppe Seyler 1993, 374, 166.

42. Jones, D.T.; Taylor, W.R.; Thornton, J.M. A model recognition approach to the prediction of all-helical membrane protein structure and topology. Biochemistry 1994, 33, 3038-3049. [CrossRef] [PubMed]

43. Stumpe, S.; Bakker, E.P. Requirement of a Large $\mathrm{K}^{+}$-Uptake Capacity and of Extracytoplasmic Protease Activity for Protamine Resistance of Escherichia Coli. Arch. Microbiol. 1997, 167, 126-136. [CrossRef] [PubMed]

44. Miesenböck, G.; De Angelis, D.A.; Rothman, J.E. Visualizing Secretion and Synaptic Transmission with pH-Sensitive Green Fluorescent Proteins. Nature 1998, 394, 192-195. [CrossRef]

45. Bertani, G. Studies on Lysogenesis. I. The Mode of Phage Liberation by Lysogenic Escherichia Coli. J. Bacteriol. 1951, 62, 293-300. [PubMed]

46. Santner, P.; Martins, J.M.d.S.; Kampmeyer, C.; Hartmann-Petersen, R.; Laursen, J.S.; Stein, A.; Olsen, C.A.; Arkin, I.T.; Winther, J.R.; Willemoës, M.; et al. Random Mutagenesis Analysis of the Influenza A M2 Proton Channel Reveals Novel Resistance Mutants. Biochemistry 2018, 57, 5957-5968. [CrossRef] [PubMed]

47. Santner, P.; Martins, J.M.d.S.; Laursen, J.S.; Behrendt, L.; Riber, L.; Olsen, C.A.; Arkin, I.T.; Winther, J.R.; Willemoës, M.; Lindorff-Larsen, K. A Robust Proton Flux (pHlux) Assay for Studying the Function and Inhibition of the Influenza A M2 Proton Channel. Biochemistry 2018, 57, 5949-5956. [CrossRef] [PubMed]

48. Lemmon, M.A.; Flanagan, J.M.; Treutlein, H.R.; Zhang, J.; Engelman, D.M. Sequence specificity in the dimerization of transmembrane alpha-helices. Biochemistry 1992, 31, 12719-12725. [CrossRef] [PubMed]

49. Lemmon, M.A.; Flanagan, J.M.; Hunt, J.F.; Adair, B.D.; Bormann, B.J.; Dempsey, C.E.; Engelman, D.M. Glycophorin A dimerization is driven by specific interactions between transmembrane alpha-helices. J. Biol. Chem. 1992, 267, 7683-7689. [PubMed]

50. Mould, J.A.; Paterson, R.G.; Takeda, M.; Ohigashi, Y.; Venkataraman, P.; Lamb, R.A.; Pinto, L.H. Influenza $\mathrm{B}$ virus BM2 protein has ion channel activity that conducts protons across membranes. Dev. Cell 2003, 5 , 175-184. [CrossRef]

51. Antoine, A.F.; Montpellier, C.; Cailliau, K.; Browaeys-Poly, E.; Vilain, J.P.; Dubuisson, J. The Alphavirus 6K Protein Activates Endogenous Ionic Conductances When Expressed in Xenopus Oocytes. J. Membr. Biol. 2007, 215, 37-48. [CrossRef]

52. Melton, J.V.; Ewart, G.D.; Weir, R.C.; Board, P.G.; Lee, E.; Gage, P.W. Alphavirus 6K Proteins Form Ion Channels. J. Biol. Chem. 2002, 277, 46923-46931. [CrossRef] [PubMed]

53. Sanz, M.A.; Pérez, L.; Carrasco, L. Semliki Forest Virus 6K Protein Modifies Membrane Permeability After Inducible Expression in Escherichia Coli Cells. J. Biol. Chem. 1994, 269, 12106-12110.

54. Premkumar, A.; Horan, C.R.; Gage, P.W. Dengue virus M protein C-terminal peptide (DVM-C) forms ion channels. J. Membr. Biol. 2005, 204, 33-38. [CrossRef]

55. Johnson, M.; Zaretskaya, I.; Raytselis, Y.; Merezhuk, Y.; McGinnis, S.; Madden, T.L. NCBI BLAST: A better web interface. Nucleic Acids Res. 2008, 36, W5-W9. [CrossRef] [PubMed]

56. Beitz, E. $\mathrm{T}_{\mathrm{E}}$ Xtopo: Shaded Membrane Protein Topology Plots in $\mathrm{L}^{\mathrm{A}} \mathrm{T}_{\mathrm{E}} \mathrm{X} 2_{\varepsilon}$. Bioinformatics 2000, 16, 1050-1051. [CrossRef] [PubMed]

57. Reuten, R.; Nikodemus, D.; Oliveira, M.B.; Patel, T.R.; Brachvogel, B.; Breloy, I.; Stetefeld, J.; Koch, M. Maltose-Binding Protein (MBP), a Secretion-Enhancing Tag for Mammalian Protein Expression Systems. PLoS ONE 2016, 11, e0152386. [CrossRef] [PubMed]

58. Astrahan, P.; Flitman-Tene, R.; Bennett, E.R.; Krugliak, M.; Gilon, C.; Arkin, I.T. Quantitative Analysis of Influenza M2 Channel Blockers. Biochim. Biophys. Acta 2011, 1808, 394-398. [CrossRef] [PubMed] 
59. Alhadeff, R.; Assa, D.; Astrahan, P.; Krugliak, M.; Arkin, I.T. Computational and Experimental Analysis of Drug Binding to the Influenza M2 Channel. Biochim. Biophys. Acta 2014, 1838, 1068-1073. [CrossRef]

60. Assa, D.; Alhadeff, R.; Krugliak, M.; Arkin, I.T. Mapping the Resistance Potential of Influenza's $\mathrm{H}^{+}$Channel Against an Antiviral Blocker. J. Mol. Biol. 2016, 428, 4209-4217. [CrossRef] [PubMed]

61. Taube, R.; Alhadeff, R.; Assa, D.; Krugliak, M.; Arkin, I.T. Bacteria-Based Analysis of HIV-1 Vpu Channel Activity. PLoS ONE 2014, 9, e105387. [CrossRef]

62. Bassford, P.; Beckwith, J. Escherichia Coli Mutants Accumulating the Precursor of a Secreted Protein in the Cytoplasm. Nature 1979, 277, 538-541. [CrossRef]

(C) 2019 by the authors. Licensee MDPI, Basel, Switzerland. This article is an open access article distributed under the terms and conditions of the Creative Commons Attribution (CC BY) license (http://creativecommons.org/licenses/by/4.0/). 